\title{
Determination of the Toxicity Cause by Trace Metals on Zebrafish (Danio rerio) Embryo
}

\author{
M. F. A. Fasmina ${ }^{1}$, S. C. Jayamanne ${ }^{1}$, N. P. P. Liyanage ${ }^{1}$, J. L. C. S. Perera ${ }^{2}$ and D. P. N. \\ De Silva ${ }^{*}$ \\ ${ }^{1}$ Faculty of Animal Science and Export Agriculture, Uva Wellassa Unuversity, Badulla 90000, Sri \\ Lanka \\ ${ }^{2}$ Graduate School of Agricultural and Life Sciences, The University of Tokyo, 1-1-1 Yayoi, Bunkyo \\ ku, Tokyo 113-0026, Japan
}

*Correspondence :

prasadi@uwu.ac.lk

Received : 2020-08-20

Accepted : 2021-03-09

Keywords :

Zebrafish embryo, Trace metals, Laboratory animals

\begin{abstract}
Water quality deterioration due to inorganic and organic pollutant is a serious issue and the presence of toxic trace metals cause a serious threat to the aquatic ecosystem. Fish embryos have gained interest in risk assessment because of their high sensitivity to pollutants and the ecological relevance. This study investigated the acute toxicity effect of trace metals Arsenic (As), Cadmium (Cd), Mercury (Hg), Lead $(\mathrm{Pb})$, Copper $(\mathrm{Cu})$ and Zinc $(\mathrm{Zn})$ on zebrafish (Danio rerio) embryo. Embryos were exposed to ten different concentrations of individual trace metals and lethality rate was recorded at 24, 48, 72 and 96 hours based on the coagulation of fertilized egg, lack of somite formation, lack of detachment of the tail and lack of heart beat. The results indicated a significant difference between the control and trace metal treated embryo $(\mathrm{P}<0.05)$ and higher mortality rate along the increase of trace metal concentration. Along with the increase of exposure time for $\mathrm{Cu}, \mathrm{Zn}$ and $\mathrm{As}$, the mortality rate became slower. Sublethal and teratogenic deformities such as growth retardation, lack of tail development, lack of eye lens (placode), yolk sac edema, pericardial edema, hemorrhages, shrinkage of chorion and scoliosis were observed in most of the trace metal treated embryos. The results showed the toxic effects to aquatic biota due to trace metals emphasizing the usefulness of zebrafish embryo model for integrated biological hazard assessment.
\end{abstract}

\section{INTRODUCTION}

Water quality deterioration is a major problem in most countries, due to organic and inorganic contaminants. Among the aquatic toxicants, trace metals cause serious impacts on the aquatic ecosystem and organisms. Metals are a natural component of the aquatic ecosystem (Goel, 2006) and trace metals such as Copper (Cu), Zinc ( $\mathrm{Zn})$ and Chromium (Cr) are important for the metabolic and other biological activities of aquatic organisms. Mercury ( $\mathrm{Hg}$ ), Lead $(\mathrm{Pb})$ and Cadmium(Cd) are biologically non-essential metals that can be toxic to biota even at a very low concentration (Mamboya, 2007). When some essential trace metals $(\mathrm{Cu}, \mathrm{Zn}$, and $\mathrm{Cr}$ ) present at high concentration, exceeding the maximum limit, can lead to toxicity (Ebrahimi and Taherianfard, 2011; 
Annabi et al., 2013a). Trace metal pollution in many aquatic environments has increased due to anthropogenic activities, mostly by the industrial effluent releasing, domestic waste and urban runoff, garbage dumping, dumping of automobile waste and mining activities (Goel, 2006; Gharedaashi et al., 2013). High accumulation of trace metal in both biotic and abiotic components causes serious health consequences. Thus, assessment of their toxicity has become an important component of water pollution monitoring. Furthermore, in Sri Lanka, Chronic Kidney Disease of unknown origin is a serious issue since the 1990s and one of the causes for this disease is due to chronic exposure of heavy metals at low levels (Bandara et al., 2008; Diyabalanage et al., 2016 and Jayalal et al., 2019). Hence determining the trace metal contamination of water and the toxic effects have become a timely necessity. In this study, zebrafish model was used as a bio-indicator to determine the effects of trace metal pollution.

Fish are the non-mammalian vertebrates used in toxicity testing (Lammer and Braunbeck, 2006). Several fish species are recommended for standard testing of chemicals. Among them, zebrafish (Danio rerio) have special characteristics, which advance its use as a model organism. The zebrafish is a tropical freshwater fish, a member of the family Cyprinidae. It is distributed throughout South and Southeast Asia (Lawrence, 2007). Traditionally it was used in molecular genetics, but now it is focusing on several chemical testing and pathological processes as it is having several specialties; small in size, all major organs present within five days postfertilization, short generation time (3-4 months), produces 300-400 eggs every two weeks, easily available non-adhesive eggs obtained from abundant spawning, translucent embryos, rapid embryonic development and lots of genome resources available.

Toxicity tests are desirable in water quality evaluation because chemical and physical tests alone are not sufficient to assess the potential effect on aquatic biota (Rice et al., 2012). Toxicity tests will reveal the organisms' sensitivity to a particular toxicant that would help us to determine the permissible limit of a toxicant in an ecosystem (Nekoubin et al., 2012). Since the implementation of the Animal Welfare Guideline 86/609/EC in 1986, the development and validation of alternatives to animal testing are strongly promoted by the European Union (EU) institutions (Council Directive, 1986). As alternative fish embryos are used instead of adult fish in present toxicology studies. Now in most of the toxicity studies zebrafish embryos are used as an alternative model for the fish acute toxicity and to determine the toxicity of pollutants. Therefore, this study was focused on the determination of the acute toxicity of $\mathrm{Cu}, \mathrm{Zn}, \mathrm{Cd}, \mathrm{As}, \mathrm{Pb}$ and $\mathrm{Hg}$ that produce a lethal effect on zebrafish embryos during short-term exposure.

\section{METHODOLOGY}

\section{Place and Time}

The experiment was carried out at the Zebrafish Research Facility of the Department of Animal Science, Faculty of Animal Science and Export Agriculture, Uva Wellassa University, Badulla, Sri Lanka.

\section{Research Materials}

To determine the toxic effects of trace metals, zebrafish embryos were used as an alternative for laboratory animal testing. Adult, wild-type zebrafish were reared at the Zebrafish Research Facility used for breeding and obtained the embryos before the blastula phase $(\sim 16$ cell stage) at 1.5 - 2 hours postfertilization.

\section{Research Design}

Acute $\mathrm{Cu}, \mathrm{Zn}, \mathrm{Pb}$, As, $\mathrm{Cd}$ and $\mathrm{Hg}$ toxicity experiments were performed for a period of four days (until hatching) using zebrafish embryos. Initially, a rangefinding test was carried out in the nominal 
concentrations (1000, 100, 10, 1 and 0.1 $\mathrm{mgL}^{-1}$ ) of the selected trace metals, and the zebrafish embryotoxicity was observed until 96 hours post-exposure. Ten eggs per concentration were exposed in a flat bottom 96 well plate and each treatment were repeated three times. Deionized water was used as a negative control and 15\% (Hassan et al., 2008) ethanol was used as the positive control (Figure 1).

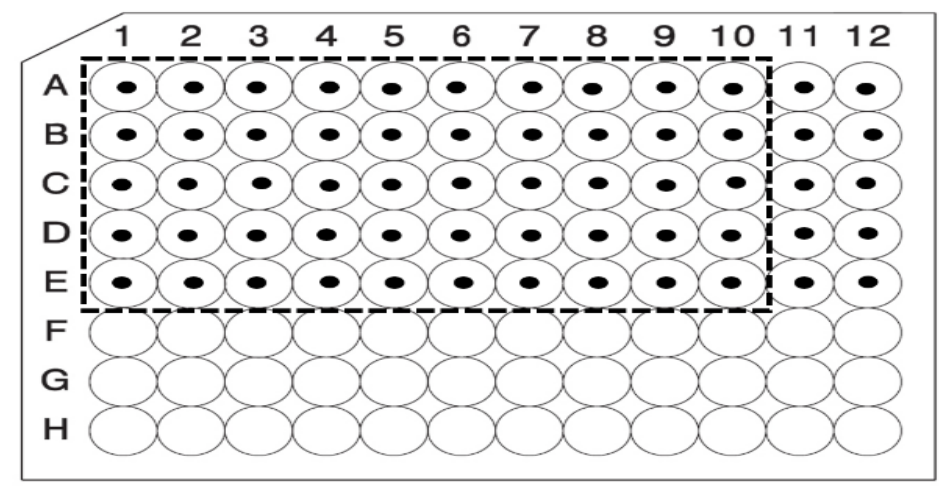

Figure 1. Schematic diagram of the range finding assay of a trace metal. A-E: Five range finding concentrations (1000, 100, 10, 1 and $0.1 \mathrm{mgL}^{-1}$ ). 1-12: Zebrafish embryos; single embryo per well is indicated by a black dot. Embryos at columns number 11 and 12 were exposed to negative control (deionized water) and positive control (15\% ethanol) respectively. Three 96 well plates with similar arrangements were used as replicates for each trace metal.

After range finding test, ten concentrations were tested against 16-cell stage zebrafish embryos for six individual trace metals. Deionized water was used as the negative control and as the internal plate control. As a positive control concentration of $15 \%$ ethanol was used. Twenty embryos $(n=20)$ per treatment (trace metal concentration) with three replicates, were randomly selected and transferred into the respective concentrations and controls. The experiment design of exposing embryos for ten concentrations of a trace metal as illustrated in Figure 2.

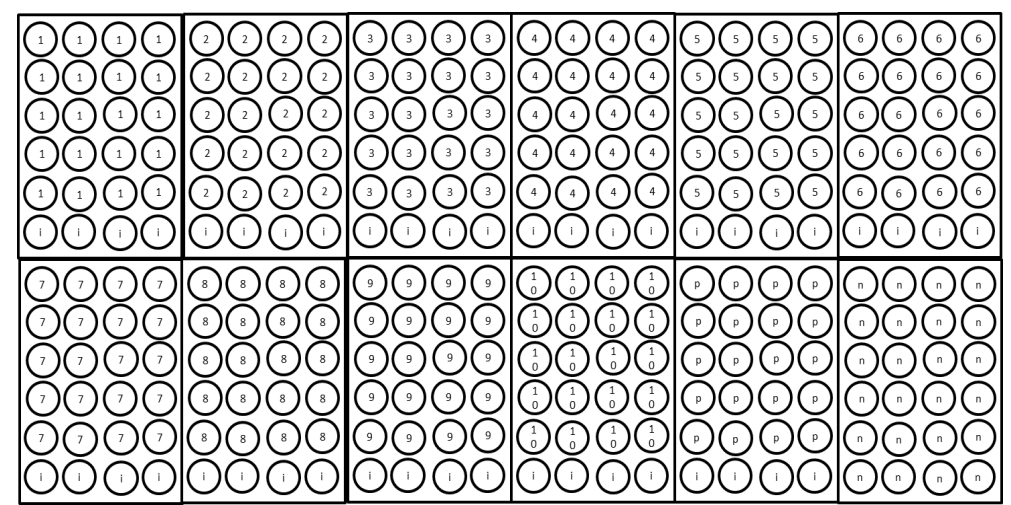

Figure 2. Schematic diagram of the experiment, 1-10 ; test concentrations, i ; internal plate control (deionized water), $\mathrm{p}$; positive control ( $15 \%$ ethanol), $\mathrm{n}$; negative control (deionized water). Single 16-cell stage zebrafish embryo was placed in each well of the 24 well plates.

\section{Work Procedures}

Apparently healthy, adult $(\sim$ six months old) male and female zebrafish were selected for breeding at a male : female ratio of $2: 1$. The spawning tank was prepared by placing spawn traps on the previous day to prevent cannibalism. 
Four males and two female fish were placed on a four-liter glass tank prepared for breeding the day before collecting eggs. The embryos were collected using a small pipette with a wide opening (Figure 3) 30 minutes after the sun rise.
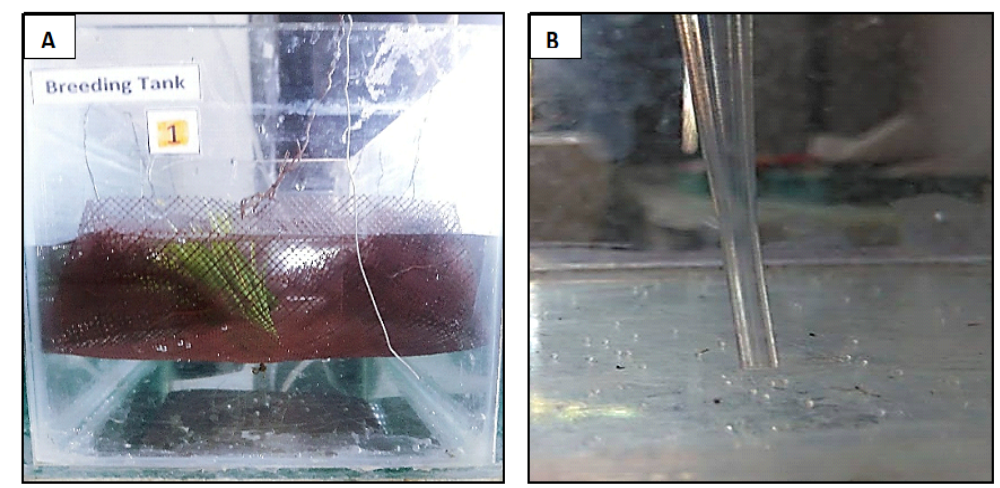

Figure 3. Preparation of spawning tank for breeding (A) and the collection of zebrafish embryos using pipette (B).

The stock solution of $1000 \mathrm{ppm}$ of selected metal ( $\mathrm{Cu}, \mathrm{Zn}, \mathrm{Pb}$, $\mathrm{Cd}$, As and $\mathrm{Hg}$ ) were prepared a day before the test by dissolving Copper sulfate $\left(\mathrm{CuSO}_{4} \cdot 5 \mathrm{H}_{2} \mathrm{O}\right)$, Zinc sulfate $\left(\mathrm{ZnSO}_{4} \cdot 7 \mathrm{H}_{2} \mathrm{O}\right)$, Lead nitrate $\left(\mathrm{Pb}\left(\mathrm{NO}_{3}\right)_{2}\right.$, Arsenic pentoxide $\left(\mathrm{As}_{2} \mathrm{O}_{5}\right)$, Cadmium chloride $\left(\mathrm{CdCl}_{2}, 1 / 2 \mathrm{H}_{2} \mathrm{O}\right)$ and Mercury chloride $\left(\mathrm{HgCl}_{2}\right)$ in deionized water. The working treatment solution was prepared daily by serial dilution from the stock solution.

Based on the results of the range finding test, ten test concentrations of $\mathrm{Cu}$ $(0.025,0.05,0.1,0.2,0.4,0.8,1.6,3.2$, 6.4 and $\left.10.0 \mathrm{mgL}^{-1}\right)$, $\mathrm{Zn}(2.0,4.0$, 8.0, 16.0, 32.0,64.0, 125.0,250.0, 500.0 and $\left.1000.0 \mathrm{mgL}^{-1}\right), \mathrm{Pb}(2.0,4.0$, 8.0, 16.0, $32.0,64.0,125.0,250.0,500.0$ and 1000.0 $\left.\mathrm{mgL}^{-1}\right)$, As (2.0, 4.0, 8.0, 16.0, 32.0,64.0,125.0,250.0, 500.0 and 1000.0 $\left.\mathrm{mgL}^{-1}\right)$, Cd (0.025, 0.05, 0.1, 0.2, 0.4, 0.8, $1.6,3.2,6.4$ and $10.0 \mathrm{mgL}^{-1}$ ) and $\mathrm{Hg}$ (0.002, 0.004, 0.008, 0.016, 0.032, 0.064, $0.125,0.250,0.500$ and $1.0 \mathrm{mgL}^{-1}$ ) were prepared by diluting the stock solution in deionized water. Deionized water was used as the negative control and the internal plate control. As a positive control concentration of $15 \%$ ethanol were used. Fertilized zebrafish embryos were immersed in the test solutions before cleavage, at $\sim 16$ cell-stage.

The fertilized embryos were distributed randomly on 24 well plates which were pre-conditioned for 24 hours and refilled with $2 \mathrm{~mL}$ per well freshly prepared test solutions as shown in figure 2 and covered with self-adhesive foil to incubate at $26 \pm 1{ }^{\circ} \mathrm{C}$.

The mortality of the fish eggs was recorded at 24, 48, 72 and 96 hours of exposure using a stereo-microscope by considering four indicators of lethality namely, coagulation of fertilized egg, lack of somite formation, lack of detachment of the tail and lack of heartbeat (OECD, 2013). The dead or coagulated eggs were removed immediately.

\section{Data Analysis}

The acute toxic effect of each metal on the zebrafish embryo was determined by Probit Analysis LC $_{50}$ determination method. Confidential limits were calculated with a 95\% confidence interval (CI) and data analysis was performed by using statistical software SPSS 15.

\section{RESULTS AND DISCUSSION}

The present study was carried out to find the acute toxicity effects of trace metals on zebrafish embryos. According to the analysis in the range finding test, the minimum concentration that can cause $100 \%$ mortality was recorded. Based on the results obtained, ranges for $\mathrm{As}, \mathrm{Pb}$ and $\mathrm{Zn}$ were below $1000.0 \mathrm{mgL}^{-1}$, for $\mathrm{Cd}$ and $\mathrm{Cu}$, it was less than $10.0 \mathrm{mgL}^{-1}$ and for $\mathrm{Hg}$, 
less than $1.0 \mathrm{mgL}^{-1}$. The relationship between the metal concentration and mortality rate of each trace metal was recorded based on the four apical endpoints. It showed that the mortality rate was increasing with the increase of trace metal concentration.

Acute toxicity of $\mathrm{As}, \mathrm{Cd}, \mathrm{Hg}, \mathrm{Pb}, \mathrm{Cu}$ and $\mathrm{Zn}$ indicated that mortality was directly proportional to the concentration of the trace metals. The Probit analysis revealed that there was a significant difference between the trace metals (As, $\mathrm{Cd}, \mathrm{Pb}, \mathrm{Hg}, \mathrm{Cu}$, and $\mathrm{Zn}$ ) and the control group $(\mathrm{P}<0.05)$. At 24 hours postfertilization (hpf), none of the embryos exposed to $15 \%$ ethanol were alive and $100 \%$ of embryos exposed to negative and internal controls and the lowest concentration of As $\left(2 \mathrm{mgL}^{-1}\right)$ and $\mathrm{Pb}(2$ $\mathrm{mgL}^{-1}$ ) were alive. After $48 \mathrm{hpf}$ one or more embryo deaths were observed in all treatments except the negative and internal controls. In general, the hatchability of the zebrafish embryo occurs after the $72 \mathrm{hpf}$, and in this study, trace metals affected the hatchability of some embryos. In negative and internal controls more than $90 \%$ of the embryos were hatched at $72 \mathrm{hpf}$, whereas in the metal treated groups low hatchability was observed at higher concentrations (supplementary data tables S1-S6).
Early hatching was also noted due to the weakening or disruption of chorionic membrane integrity by trace metals (Weis, 2014). Chorion, which is a semipermeable protective layer in fish embryos unable to prevent trace metal penetration due to the formation of pores, altering the permeability of the chorionic membrane. However, chorion act as a barrier to prevent Cd transfer to the developing embryo (Shazili and Pascoe, 1986). In zebrafish, it was reported that $61 \%$ of total $\mathrm{Cd}$ was retained by the chorion (Annabi $e t$ al., 2013b) which is also shown from the findings of this study.

\section{Median Lethal Concentration}

The median lethal concentration $\left(\mathrm{LC}_{50}\right)$ of each trace metal at $24 \mathrm{hpf}, 48$ hpf, $72 \mathrm{hpf}$, and $96 \mathrm{hpf}$ are summarized in Table 1 . According to the analysis of $\mathrm{LC}_{50}$, $\mathrm{Hg}$ is highly toxic to the zebrafish embryo followed by $\mathrm{Cu}, \mathrm{Cd}, \mathrm{Zn}$, As and $\mathrm{Pb}$. The toxicity trend of $\mathrm{LC}_{50}$ at $96 \mathrm{hpf}$ observed was $\mathrm{Hg}\left(0.0217 \mathrm{mgL}^{-1}\right)<\mathrm{Cu}\left(0.099 \mathrm{mgL}^{-}\right.$ $\left.{ }^{1}\right)<\mathrm{Cd}\left(0.407 \mathrm{mgL}^{-1}\right)<\mathrm{Zn}\left(14.021 \mathrm{mgL}^{-}\right.$ $\left.{ }^{1}\right)<$ As $\left(34.840 \mathrm{mgL}^{-1}\right)<\mathrm{Pb}\left(41.697 \mathrm{mgL}^{-}\right.$ $\left.{ }^{1}\right)$. $\mathrm{LC}_{50}$ did not change over time in $\mathrm{Cu}, \mathrm{Zn}$ and As (95\% confidence limits) indicating the potential toxicity to early developmental stages in zebrafish embryos (Table 1).

Table 1. Summarized LC $_{50}$ value of trace metals on Danio rerio embryo for a period of 24 -96 hpf.

\begin{tabular}{ccccc}
\hline \multirow{2}{*}{ Trace metals } & $24 \mathrm{hpf}$ & $\mathrm{LC}_{50}(95 \%$ confident limits - lower, upper) & \\
& 0.0397 & 0.0229 & $72 \mathrm{hpf}$ & $96 \mathrm{hpf}$ \\
\hline $\mathrm{Hg}$ & $(0.0324,0.0488)$ & $(0.0245,0.0367)$ & $(0.0182,0.0263)$ & $(0.0180,0.0260)$ \\
& 0.1735 & 0.1306 & $0.0991^{\mathrm{a}}$ & $0.0991^{\mathrm{a}}$ \\
$\mathrm{Cu}$ & $(0.1498,0.2011)$ & $(0.1128,0.1512)$ & $(0.0844,0.1157)$ & $(0.0844,0.1157)$ \\
& 0.5660 & 0.464 & 0.418 & 0.407 \\
$\mathrm{Cd}$ & $(0.4339,0.741)$ & $(0.3505,0.613)$ & $(0.3152,0.550)$ & $(0.3072,0.536)$ \\
& 23.083 & 17.080 & $14.021^{\mathrm{b}}$ & $14.021^{\mathrm{b}}$ \\
$\mathrm{Zn}$ & $(18.871,28.13)$ & $(13.936,20.801)$ & $(11.347,17.147)$ & $(11.347,17.147)$ \\
& 42.915 & 38.313 & $34.840^{\mathrm{c}}$ & $34.840^{\mathrm{c}}$ \\
$\mathrm{As}$ & $(36.223,50.97)$ & $(32.007,45.98)$ & $(28.903,42.08)$ & $(28.903,42.08)$ \\
& 113.8 & 63.90 & 43.75 & 41.70 \\
$\mathrm{~Pb}$ & $(88.5,149.6)$ & $(50.81,81.0)$ & $(35.75,53.71)$ & $(33.97,51.34)$ \\
\hline
\end{tabular}

\footnotetext{
${ }^{a}$ There is no difference in the $\mathrm{LC}_{50}$ value of the $\mathrm{Cu}$ at 72 and $96 \mathrm{hpf}$ after exposure

${ }^{\mathrm{b}}$ There is no difference in the $\mathrm{LC}_{50}$ value of the $\mathrm{Zn}$ at 72 and $96 \mathrm{hpf}$ after exposure

${ }^{c}$ There is no difference in the $\mathrm{LC}_{50}$ value of the $\mathrm{As}$ at 72 and $96 \mathrm{hpf}$ after exposure
} 
In this study, the most toxic trace metal to zebrafish embryo was $\mathrm{Hg}$. The $\mathrm{LC}_{50}$ values of $\mathrm{Hg}$ at 24, 48, 72 and $96 \mathrm{hpf}$ were less than $0.04 \mathrm{mgL}^{-1}$. It shows that even at lower concentrations it can cause a high mortality rate on zebrafish embryos. Previous studies reported that $\mathrm{LC}_{50}$ of zebrafish embryos exposed to mercuric chloride $\left(\mathrm{HgCl}_{2}\right)$, at $96 \mathrm{hpf}$ was $0.07 \mathrm{mgL}^{-1}$ (Vutukuru and Basani, 2013). There are some studies on the toxicity effect of $\mathrm{Hg}$ on some fish species embryo, For example, $\mathrm{LC}_{50}$ value of Rainbow trout, channel catfish, Goldfish and Largemouth bass has been reported as below $0.7 \mu \mathrm{gL}^{-1}$, $0.3 \mu g \mathrm{~L}^{-1}, \quad 0.7 \mu \mathrm{gL}^{-1}$ and $5.3 \mu \mathrm{gL}^{-1}$ respectively (Boening, 2000).

$\mathrm{Cu}$ and $\mathrm{Cd}$ are also highly toxic to aquatic organisms. However, $\mathrm{Cu}$ caused more toxicity to the fish compared to $\mathrm{Cd}$. The results of many studies showed higher toxicity of $\mathrm{Cu}$ compared to Cd (Zhu et al., 2011; Witeska et al., 2014; Yang, 2014) including the findings in this study. There is an increasing concern about the As contamination in the water. Various researchers use different animal models to investigate the basic mechanism of As mediated developmental toxicity (Rodriguez et al., 2002; Ghandi and Kumar, 2013). This study showed a higher $\mathrm{LC}_{50}$ value for the As compared to $\mathrm{Hg}, \mathrm{Cd}$, $\mathrm{Zn}$ and $\mathrm{Cu}$ indicating that As was less toxic to zebrafish embryos (Spehar et al., 1980). $\mathrm{Pb}$ lacks biological functions and is toxic for aquatic organisms even at a small dose (Osman, 2007). According to the toxicity assay, the least toxic metal on zebrafish embryos was $\mathrm{Pb}$. However, early exposure to $\mathrm{Pb}$ may cause severe defects (Weis and Weis, 1977) which is also observed in this study.

\section{Sub- Lethal and Teratogenic Effects}

In the normal development of zebrafish embryo, somite formation starts after the $10 \mathrm{hpf}$, and the tail development, tailbud detachment from the yolk sac can be observed after $24 \mathrm{hpf}$ followed by all the other major organ development which can be observed within five days. Hence, lack of somite formation and tail detachment are considered features of the dead embryos (Kimmel et al., 1995; Lammer, 2009).

During the zebrafish embryotoxicity test, several sub-lethal and teratogenic endpoints were observed in addition to the four major lethal endpoints. In negative and internal controls, sub-lethal or teratogenic endpoint was absent and normal age-specific developmental features such as straightening of the body axis from its curvature around the yolk sac, blood vascular circulation, heartbeat, and epidermal pigmentation were observed.

Zebrafish embryos at $72 \mathrm{hpf}$ displayed normal development of all major organs in negative and internal control groups and the lowest concentration of As $\left(2 \mathrm{mgL}^{-1}, 4 \mathrm{mgL}^{-1}\right), \mathrm{Pb}$ $\left(2 \mathrm{mgL}^{-1}, 4 \mathrm{mgL}^{-1}\right)$, and $\mathrm{Zn}\left(0.025 \mathrm{mgL}^{-1}\right.$, $\left.0.05 \mathrm{mgL}^{-1}\right)$. However, several deformities were observed in the other treatment groups including growth retardation, shrinkage of chorion, scoliosis, pericardial edema, yolk sac edema, lack of pigmentation, tail deformities, hemorrhages, missing formation of lens Placodes and lack of otoliths (Figure 3). 

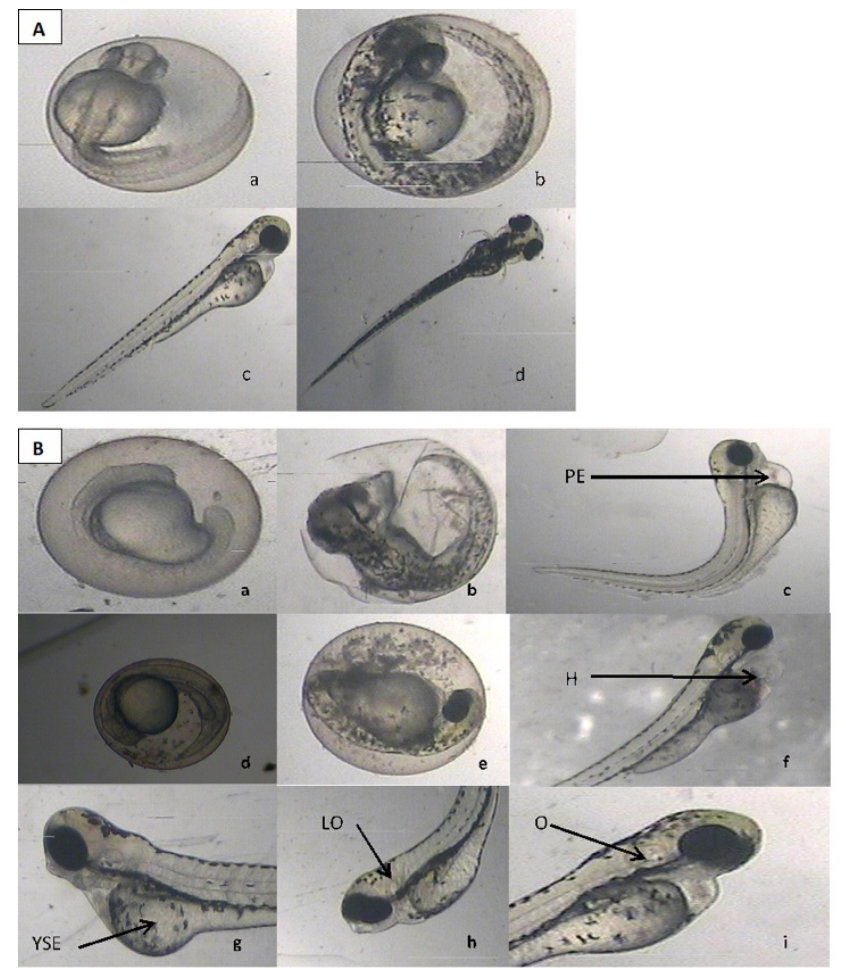

Figure 3. Normally developed zebrafish embryo after 24 hpf (a), 48 hpf (b), $72 \mathrm{hpf}$ (c), and $96 \mathrm{hpf}$ (d) (A). Sub-lethal and teratogenic endpoints ; (a) Growth retardation, (b) Shrinkage of chorion, (c) Scoliosis and Pericardial edema (PE), (d) Lack of pigmentation, (e) tail deformities, (f) Hemorrhages (H), (g) Yolk sac edema (YSE), (h) Lack of otoliths (LO), (i) Normally developed zebrafish embryo (otolinth - O) after 96 hpf (B)..

Skeletal deformities in fish are a good bioindicator of pollution (Villeneuve et al., 2005). Damage of the vertebral column expressed as the curvature of the larval body axis (scoliosis) occurss due to almost all heavy metal toxicities (Osman, 2007). Scoliosis observed in this study on metal exposed embryos implicates the potential risk of toxicity to aquatic biota. Growth retardation was mainly present in embryos exposed to $\mathrm{Cu}$ and $\mathrm{Cd}$, which is known to be the most powerful growth inhibitor causing damage to the vertebral column by inhibition of collagen synthesis (Sikorska and Wolnicki, 2006). Pb causes scoliosis by impairing ionic regulation (Słomińska and Jezierska, 2000; Khayatzadeh and Abbasi, 2010) while Cd, $\mathrm{Pb}, \mathrm{Zn}$ and $\mathrm{As}$ are considered as neurotoxic, having the ability to fracture the vertebrae through tetanic muscular contraction (Villeneuve et al., 2005). Scoliosis was one of the main observations found in this study from all trace metals tested.

The tail deformities are caused by the inability of metal treated embryos to express the evenskippid gene, which is important during the tail development, while pigmentation of the zebrafish skin is controlled by Melanocyte Stimulating Hormone (aMSH) and MelaninConcentrating Hormone (MCH). As a result of the metal treatment, synthesis of particular gene and hormones were impaired inhibiting the tail detachment and pigment development were inhibited (Osman, 2007). Hemorrhages usually occur as a result of fractures at the base of the neural or haemal arch of the centrum (Villeneuve et al., 2005). In this study, hemorrhages were observed mostly in the $\mathrm{Pb}$ treated embryos. Pericardial edema, which is a non-specific symptom seen in response to inorganic or organic 
pollutants was also found in zebrafish embryos exposed to $\mathrm{Zn}, \mathrm{Cu}$, and As.

Lack of otolith formation was recorded in the embryos treated with $\mathrm{Cd}$ and $\mathrm{Cu}$. Many metals directly enter the olfactory system where they can disrupt normal function by accumulating in and damaging cells of the olfactory system. It can disrupt the transmission of information from the olfactory lobes to higher levels of the brain (Weis, 2014).

Zebrafish embryos revealed a lot of toxic signs and symptoms indicating the risks to the aquatic environment by metal pollution even at a low concentration. Hence, the findings and the methods used in this study can be adhered to for water quality testing and determining aquatic environmental pollution.

\section{CONCLUSION}

Based on $\mathrm{LC}_{50}$ values, sub-lethal and teratogenic effects in zebrafish embryos, $\mathrm{Hg}$ was highly toxic followed by $\mathrm{Cu}, \mathrm{Cd}$, $\mathrm{Zn}$, As and $\mathrm{Pb}$. The $\mathrm{LC}_{50}$ value of each trace metal was increasing with the increasing concentration and $\mathrm{Cu}, \mathrm{Zn}$ and As remained static after 72 hpf. Sub-lethal and teratogenic deformities such as growth retardation, lack of tail development, lack of eye lens (placode), yolk sac edema, pericardial edema, hemorrhages, shrinkage of chorion, and scoliosis were observed in metal treated embryos.

\section{ACKNOWLEDGMENT}

The authors would like to acknowledge the Vice-Chancellor and staff members of the Faculty of Animal Science and Export Agriculture, Uva Wellassa University, Sri Lanka.

\section{REFERENCES}

Annabi, A., Said, K. and Messaoudi, I., 2013a. Cadmium: Bioaccumulation, Histopathology and Detoxifying Mechanisms in Fish. American Journal of Research Communication, 1(4), pp.60-79. http://www.usajournals.com/wp-content/uploads/ 2013/03/Annabi_Vol14_1.pdf
Annabi, A., Said, K. and Messaoudi, I., 2013b. Cadmium: Toxic effects and physiological impairment in fish. International Journal of Advanced Research, 1(3), pp.372-382. https:// www.journalijar.com/article/86/ca dmium:-toxic-effects-and-physiologi cal-impairments-in-fishes/

Bandara, J.M.R.S., Senevirathna, D.M.A.N., Dasanayake, D.M.R.S.B., Herath, V., Bandara, J.M.R.P. and Abeysekara, T., 2008. Chronic renal failure among farm families in cascade irrigation systems in Sri Lanka associated with elevated dietary cadmium levels in rice and freshwater fish (Tilapia). Environmental Geochemistry and Health, 30(5), pp.465-478. https:// doi.org/10.1007/s10653-007-91296

Boening, D.W., 2000. Ecological effects, transport, and fate of mercury: A general review. Chemosphere, 40(12), pp.1335-1351. https://doi. org/10.1016/S0045-6535(99)0028 3-0

Council Directive 86/609/EEC, 1986. European Union. Website. https://eu r-lex.europa.eu/legal-content/EN/A LL/?uri=CELEX\%3A31986L0609. Accessed on $12^{\text {th }}$ July 2019.

Diyabalanage, S., Navarathna, T., Abeysundara, H.T.K., Rajapakse, S. and Chandrajith, R., 2016. Trace elements in native and improved paddy rice from different climatic regions of Sri Lanka: implications for public health. SpringerPlus, 5(1), p. 1864. https://doi.org/10.1186/s 40064-016-3547-9

Ebrahimi, M. and Taherianfard, M., 2011. The effects of heavy metals exposure on reproductive systems of cyprinid fish from Kor River. Iranian Journal of Fisheries Sciences, 10(1), pp.1326. http://jifro.ir/article-1-121-en.h tml

Ghandi, D.N. and Kumar, R., 2013. Arsenic toxicity and neurobehaviour: A review. Innovations in pharmaceutical and 
pharmacotherapy, 1(1), pp.1-15. http://www.innpharmacotherapy.c om/Archive.aspx? IssueID $=1$

Gharedaashi, E., Imanpour, M.R. and Taghiadeh, V., 2013. Determination of median lethal concentration $\left(\mathrm{LC}_{50}\right)$ of copper sulfate and lead nitrate and effects on behavior in Caspian Sea kutum (Rutilus frisii kutum). Journal of toxicology and environmental health Ssciences, 5(1), pp.12-16. https://doi.org/10.5897/ JTEHS12.027

Goel, P.K., 2006. Water pollution cause, effect and control. New Age International Publisher. New Delhi, India.

Hassan, S.M., Moussa, E.A. and Abbott, L.C., 2008. Effect of Quillaja saponin (Quillaja saponaria) on early embryonic zebrafish (Danio rerio) development. International Journal of Toxicology, 27, pp.273-278. https://doi.org/10.1080/10915810 802152129

Jayalal, T.B.A., Bandara, T.W.M.A.J., Mahawithanage, S.T.C., Wansapala M.A.J. and Galappaththi, S.P.L., 2019. A quantitative analysis of chronic exposure of selected heavy metals in a model diet in a CKD hotspot in Sri Lanka. BMC Nephrology, 20(218), pp.1-14. https: //doi.org/10.1186/s12882-019-13 71-5

Khayatzadeh, J. and Abbasi, E., 2010, April. The effects of heavy metals on aquatic animals. In The 1st International Applied Geological Congress, Department of Geology, Islamic Azad University-Mashad Branch, Iran (Vol. 1, pp.26-28).

Kimmel, C.B., Ballard, W.W., Kimmel, S.R., Ullmann, B. and Schilling, T.C., 1995. Stages of embryonic development of the zebrafish. Developmental dynamics, 203, pp.253-310. https://doi.org/10.100 2/aja.1002030302

Lammer, E., 2009. Refinement of the fish embryo toxicity test (FET) with zebrafish (Danio rerio): Is it a real replacement of the acute fish toxicity test?. Doctor of Natural Science Dissertation, Carola University of Heidelberg, Germany. p.150 https://doi.org/10.11588/heidok.0 0009552

Lammer, E. and Braunbeck, T., 2006. Fish embryo toxicity assay. Department of Zoology, University of Heidelberg, Germany.

Lawrence, C., 2007. The husbandry of zebrafish (Danio rerio): A review. Aquaculture, 269(1-4), pp.1-20. https://doi.org/10.1016/j.aquacult ure.2007.04.077

Mamboya, F.A., 2007. Heavy metal contamination and toxicity studies of macroalgae from the Tanzanian Coast. Stockholm University, Sweden.

Nekoubin, H., Gharedaashi, E., Hosseinzadeh, M. and Imanpour, M.R., 2012. Determination of $\mathrm{LC}_{50}$ of lead nitrate and copper sulphate in common carp (Ciprinus carpio). American-Eurasian Journal of Toxicological Sciences (AEJTS), 4(2), pp.60-63. DOI: 10.5829/idosi.aejts. 2012.4.2.6297

Organization for Economic Cooperation and Development (OECD), 2013. OECD Guidelines for testing of chemicals-Fish Embryo Acute Toxicity (FET) Test, OECD Publishing, Paris, p.236. https://doi.org/10.1787/97 89264203709-en

Osman, A.G.E.K.M., 2007. Embryo-toxic effects of lead nitrate of the African catfish (Clarias gariepinus). Doctor of Agriculture Dissertation, Department of Biology and Ecology of Fishes, Al-Azhar University (Assiut branch), 71524 Assiut, Egypt. p.140.

Rice, E.W., Baird, P.B., Eaton, A.D. and Lesceri, L.S., 2012. Toxicologies. Standard method for the examination of water and wastewater. $23^{\text {rd }} \mathrm{Ed}$. American Water Work A ssociation, American public work association/ Water environment federation. 
Rodriguez, V.M., Carrizales, L., Mendoza, M.S., Fajardo, O.R. and Giordano, M., 2002. Effects of sodium arsenite exposure on development and behavior in the rat. Neurotoxicology and Teratology, 24(6), pp.743-750. https://doi.org/10.1016/S0892-03 62(02)00313-6

Shazili, N.A.M. and Pascoe, D., 1986. Variable sensitivity of rainbow trout (Salmo gairdneri) eggs and alevins to heavy metals. Bulletin of Environmental Contamination and Toxicoogyl, 36, pp.468-474. https:// doi.org/10.1007/BF01623536

Sikorska, J. and Wolnicki, J., 2006. Cadmium Toxicity to Rudd (Scardinius erythrophthalmus (L.)) Larvae After Shortterm Exposure. Archives of Polish Fisheries, 14(1), pp.15-27. http://fal.infish.com.pl/i ndex.php/FisheriesAndAquaticLife/ article/view/180

Słomińska, I. and Jezierska, B., 2000. The effect of heavy metals on postembryonic development of common carp, Cyprinus carpio L. Fisheries \& Aquatic Life, 8(1), pp.119-128. http://www.fal.infish.c om.pl/index.php/FisheriesAndAqua ticLife/article/view/43

Spehar, R.L., Fiandt, J.T., Anderson, R.L. and DeFoe, D.L., 1980. Comparative toxicity of arsenic compounds and their accumulation in invertebrates and fish. Archives of Environmental Contamination and Toxicology, 9, pp.53-63. https://doi.org/10.1007/ BF01055499

Villeneuve, D.L., Curtis, L.R., Jenkins, J.J., Warner, K.E., Tilton, Kent, M. L., Watral, V.G., Cunningham, M.E., Markle, D.F., Sethajintanin, D., Krissanakriangkrai, O., Johnson, E.R., Grove, R. and Anderson, K.A., 2005. Environmental Stresses and Skeletal Deformities in Fish from the Willamette River, Oregon. Environmental science \& technology, 39(10), pp.3495-3506. https://doi. org/10.1021/es048570c
Vutukuru, S.S. and Basani, K., 2013. Acute effect of mercuric chloride on glycogen and protein content of zebrafish (Danio rerio). Journal of Environmental Biology, 34(2), pp.277-281. https://pubmed.ncbi.nl m.nih.gov/24620592/

Weis, J.S., 2014. Delayed behavioral effects of early life toxicant exposures in aquatic biota. Toxics., 2(2), pp.165-187. https://doi.org/1 $0.3390 /$ toxics 2020165

Weis, J.S. and Weis, P., 1977. Effects of heavy metals on development of the killifish, Fundulus heteroclitus. Journal of fish biology, 11 (1), pp.4954. https://doi.org/10.1111/j.1095 -8649.1977.tb04097.x

Witeska, M., Sarnowski, P., Ługowska, K. and Kowal, E., 2014. The effects of cadmium and copper on embryonic and larval development of ide Leuciscus idus L. Fish Physiology and Biochemistry, 40, pp.151-163. https: //doi.org/10.1007/s10695-013-98 $32-4$

Yang, J.L., 2014. Comparative acute toxicity of gallium (III), antimony (III), indium (III), cadmium (II), and copper (II) on freshwater swamp shrimp (Macrobrachium nipponense). Biological Research, 47(1), p.13. https://doi.org/10.118 6/0717-6287-47-13

Zhu, B., Wu, Z.F., Li, J. and Wang, G.X., 2011. Single and joint action toxicity of heavy metals on early developmental stages of Chinese rare minnow (Gobiocypris rarus). Ecotoxicology and Ennvironment Safety, 74(8), pp.2193-2202. https: //doi.org/10.1016/j.ecoenv.2011.0 7.033 